\title{
Strategies for Continuing Education of Elementary and Middle School Teachers Relying on Information Technology
}

\author{
Xinyi Zhou, ${ }^{1}$ Hongqin Meng, ${ }^{2}$ Hongtao $\mathrm{Ma}^{3}$ \\ 1. Chengdu Normal University, Chengdu, China \\ 2. Shishi Tianfu High School, Chengdu, China \\ 3. Chengdu ELDU Wisteria Elementary School, Chengdu, China
}

\begin{abstract}
In the context of "Internet+", accelerating the in-depth integration of teachers' continuing education and information technology, improving the comprehensive quality and abilities of elementary and middle school teachers, and promoting the development of elementary and middle school teachers have become new tasks for continuing education for teachers. Based on the difficulties and challenges of continuing education for teachers in the context of the internet, clarify the new requirements for teachers' ability in the context of the internet, and explore how to integrate Internet technology with continuing education for teachers. Use Internet technology to improve the quality and effectiveness of continuing education for teachers, with a view to promote the wisdom generation of teachers' continuing education.
\end{abstract}

Sci Insigt Edu Front 2019; 4(2):435-444.

Doi: 10.15354/sief.19.ar270.

Keywords: Information Technology; Elementary and Middle School Teachers; Continuing Education for Teachers; Integration Strategies

Correspondence to: Hongtao Ma, Chengdu ELDU Wisteria Elementary School, Chengdu, China,Email:442188099@qq.com.

About the Authors: Xinyi Zhou, Network and Information Center, Chengdu Normal University, Chengdu, China, Email: neemo@126.com.

Hongqin Meng, Shishi Tianfu High School, Chengdu, China, Email: 2917173407@qq.com.

Conflict of Interests: None. 
INCE the 1960s, teacher training and development have gradually received attention from countries around the world. The United States, the United Kingdom, France, Japan and other countries have successively established teacher promotion and training centers, learning and teaching research centers, teacher development centers and other departments to be responsible for teacher training and development, and have stipulated in legislation the duration of teachers' on-the-job training and training systems. . In 1985, China relied on Beijing Normal University and Wuhan University to establish a national teacher training center, and in 2012, it started the construction of a teacher teaching development demonstration center to ensure teacher education and training (Gou, et al., 2019).

With the continuous development of network technology, "Internet+ Education" has been becoming a new opportunity for profound changes in teachers' continuing education. The "Opinions of the CPC Central Committee and the State Council on Deepening the Reform of the Teachers in the New Era in 2018" further clearly stated that training methods should be changed, the organic integration of information technology and teacher training should be promoted, and a combination of online and offline training (State Council of the CPC Central Committee, 2018).

Emerging education supply methods have brought new opportunities and challenges to teachers' continuous education, whether it is ideas, laws, content, or models. How to effectively integrate the "Internet+" technology into teacher training and break the limitations of traditional teacher training is an urgent problem.

\section{Difficulties and Challenges of Continuing Education for Elementary and Middle School Teachers}

\section{The Dilemma of the Traditional Teacher Continuing Educa- tion Model Highlights}

Some scholars believe that the traditional model of continuing education for teachers in China is facing realistic problems such as uneven participation in training opportunities, single training methods, low enthusiasm of teachers, generalization and fragmentation of training courses, and weak radiation links after training (Zhang \& Sun, 2019). Zhu pointed out, "Traditional training is often centered on experts, mainly teaching by experts, and is generally concentrated in face-to-face classes. The training scale is small. If the training scale is expanded, the training effect will be affected, and the training cost will be higher. Moreover, the training time is fixed, the training courses and teachers are also arranged by the training organization before the class, and the training interaction is weak" (Zhu, 2019).

Some scholars believe that there is a serious disconnect between theory and practice in traditional teacher continuing education. In the "Internet+" era, it lacks the ability to keep up with the times in terms of training organization and resource integra- 
tion, and is facing competition from diversified continuing education models such as well-known universities and large training companies, making traditional teacher continuing education models challenged by multiple factors (Shi \& Yuan, 2017).

\section{Realistic Challenges Facing Teachers' Continuing Education in the New Environment}

"Internet, instant messaging, mobile terminals, big data, cloud computing, MicroBlog (Weibo; Chinese Twitter), MOOC, and micro-learning have made today's society into a diverse era, and they are changing the current teaching philosophy and learning styles" (Yu, 2014). The use of information technology for teaching is also a kind of teacher professional quality, but because some teachers lack basic knowledge of information technology, interconnected technology has become a factor hindering teacher development in teaching (Wai, 2018).

At the same time, modern information technology has not only changed the traditional education model and learning environment, but also fundamentally changed the ecology of education. The channels and channels for students to obtain information are sufficient and diverse. Teachers' teaching is no longer the only way for students to acquire knowledge. Therefore, some scholars point out that "the authority of teachers in the Internet era is being challenged, the teaching difficulty of teachers is doubled, and the pressure on teachers' professional development is huge" ( $\mathrm{Ji}, 2005)$.

On the one hand, the great development and prosperity of information technology, and on the other hand, teachers face a lot of practical problems in reality. Teachers' continuing education, as an important part of education, must face a series of adjustments brought by the Internet era, change traditional educational thoughts, and plan new strategic development directions.

\section{New Requirements for teachers' Ability in the "Inter- net+" Background}

The application of "Internet+" in the education field is mainly to reform traditional education models through cloud computing, big data and other platforms, and to optimize and integrate online education resources. This is an epoch-making leap for the development of education. In particular, the application of new technologies in education has made education present a new development form and put forward new requirements for teachers.

\section{Introduce "Internet+" Thinking and Change Education Con- cepts}


The development of education informatization will inevitably bring a great impact on traditional education. As teachers, they must consciously and fully recognize the epochal and necessity of their role change, and strive to become a new type of teacher that meets the requirements of the times (Zeng, 2006).

Improve students" learning effectiveness and promote the development of students in cognitive areas (such as thinking ability, memory ability, imagination ability, observation ability, etc.) and non-cognitive areas (such as interest, personality, social, belief, emotion, morality, etc.) has been becoming the value of teacher education worldwide (Xie, 2017).

In the traditional concept of education, education tends to instill students" knowledge and ignores the thinking process that guides students to pursue knowledge. Classroom education under the new curriculum reform encourages teachers to cultivate students" ability to independently explore knowledge, constructs knowledge and ways of thinking, and gives priority to the development of human life and personality. The new educational values require teachers to pay attention to and respect the individual life of students, take students as the center, and pay attention to the openness and generability of the curriculum. A series of transformation is happening, such as from knowledge transfer to the establishment of moral education talents, from knowledge infusion to student capacity generation, from skills transfer to student thinking training, from cold book education to temperature-based emotional education. Therefore, it emphasizes the personality development, personality cultivation and thinking development of students.

Therefore, some scholars believe that from the perspective of the "Internet+" concept, teacher education should always be guided by the "Internet+" concept. They should understand and master the frontiers of social and disciplinary development, continuously update the curriculum content, and adjust the curriculum system in a timely manner to maintain the curriculum in its timeliness and advancement (Manuela, 2013). At the same time, teachers must learn to use the Internet platform to make personalized and diversified teaching more practical and feasible, so as to create a new teaching ecology under the "Internet+" background.

\section{Changing Teacher Roles Based on Wisdom Education}

Smart education is the use of new information technologies such as the Internet of Things, cloud computing, big data, and augmented reality to build a resource-sharing smart teaching ecological environment suitable for adaptive learning, integrate smart education theory, and use data mining and analysis technology to analyze and learn Learners, explore the inherent factors affecting learning, intelligently provide personalized learning support services, guide learners to invest limited psychological resources into deeper learning, and cultivate highly intelligent and innovative talents. In the environment of smart education, teachers need to reposition their roles (Chen, 2015). 
Teachers are no longer dominant and authoritative in educational relations, and the democracy of education is stronger than ever. Some professional functions of teachers, such as knowledge teaching and homework correction, can also be gradually replaced by machines and technologies, and the irreplaceability of teacher profession has changed greatly. Therefore, the role of teachers should be "transformed from teaching technicians to facilitators of student development" (Xie, 2017).

\section{Using Information Technology to Transform Teaching Meth- ods}

The new curriculum reform clearly puts forward that "we must gradually realize the changes in student learning methods, teacher teaching methods, and teacher-student interaction methods." In traditional classrooms, teachers use chalk, blackboards, or multimedia as media to present content that is constrained by space and time. Classroom interactions also have prominent problems such as imbalanced directions, monotonous forms, and insufficient depth. Deeply integrate information technology with classroom teaching, realize class-centered, content-connected, and internet devices as carriers, seamlessly link learning before, during and after class, and make advanced science and technology serve education and teaching To achieve precise teaching (He, et al., 2019).

Taking a middle school in Chengdu, Sichuan Province, China as an example, the middle school teacher prepares the lesson before class, uploads data with the help of the platform, sets up a question bank based on knowledge points, and sets up exercise books. At the same time, the teacher arranges the preview content for the students through the platform, guides students to become interested in the preview content through situation construction and question stimulation, guides students to "learn first" before class, and completes the preview materials and tests pushed by the teacher. Through data collection and analysis technology, the teacher sees the results of student previews in the platform and adjusts the teaching plan in a targeted manner according to the academic situation. During the lesson, the teacher used internet devices such as tablets or clickers to interact with the students, timely discover the knowledge, key points, and difficult problems that the students did not master, and led the students to explain their knowledge and understanding of related issues, and then discover new ones. In the feedback section after class, the teacher can check the completion status of each student or the entire student's unified homework through the platform or mobile terminal, and timely understand the students" grasp of the knowledge they have learned, and then push personalized homework for students at different levels in order to In order to promptly check for omissions and fill gaps, guide students to form a comprehensive construction and deeper understanding of knowledge.

Internet makes education much more convenient and new requirements are put forward for teachers' training. Teachers are required to use information technology such as education platforms to improve classroom teaching efficiency, enable students to teach in a targeted manner, and achieve personalized development of students. 


\section{Strategies for Deep Integration of teachers' Continu- ing Education and the Internet}

In the context of the "Internet+ Education" era, basic education places higher demands on teachers' capabilities. Teachers' continuing education, as an important part of education, also needs to be changed and adjusted. Use network technology to carry out continuing education for teachers, promote the generation, cohesion and sharing of highquality training resources, and organize teachers to conduct effective online and offline communication. In order to promote the in-depth integration of teacher training and teaching practice, fully respect the learners' personal characteristics and willingness to design training methods and progress, and comprehensively promote the reform and innovation of teacher continuing education.

\section{Promote the Construction of Online Platforms and Build a Mixed-Teacher Continuing Education Teaching Model}

The blended teaching mode is formed along with the development of centralized faceto-face teaching and network training, which refers to a combination of online learning and classroom teaching. Some scholars believe that focusing on face-to-face teaching focuses on problem diagnosis, expert guidance, case demonstration, and practical experience to help teachers establish goals, master methods and strategies, clarify development paths, and form improvement plans. However, concentrated face-to-face teaching is difficult to resolve the contradictions between engineering and learning, and it is difficult to reduce the cost of continuing education. The online training mainly uses the online platform to provide the participating teachers with online learning course resources, realize the sharing and interactive exchange of online course learning resources, and ensure the effective promotion of training. Through the organic combination of online learning and classroom face-to-face teaching, there are real-time and non-realtime, synchronous and asynchronous teacher lectures. Discussion learning, collaborative learning, group learning based on the concept of "collaboration", and traditional and autonomous learning around the network can be conducted. Therefore, some experts and scholars have proposed that "the mixed teaching model is an effective way to guarantee the quality of teachers' continuing education" (Liu, et al., 2018).

The construction of the teacher continuing education platform is the premise for the development of a mixed teacher continuing education model, and it is the preliminary basic project of "Internet+" and teacher continuing education (Tang, et al., 2015). To realize the continuing education on the Internet, it needs to meet the characteristics of large-scale training, extensive coverage, personalized training, optimized training funds, and balanced high-quality resources. Therefore, the creation of online continuing education platform requires both advanced technology and the characteristics of elementary and middle school teacher training. 


\section{Using Big Data Analysis Technology to Achieve Personalized Teacher Continuing Education}

Teachers' continuing education needs to be based on teachers' actual needs. Traditional teacher education is restricted by technology, and demand surveys are often conducted by random sampling, questionnaires, individual interviews, and classroom observations. Because the survey sample is small and the data is small, it is impossible to obtain the true needs of teachers' continuing education in a comprehensive and effective manner, which causes the problem of disconnected training programs and training courses and training content from real needs. Collect the big data of teacher training needs through the platform, use the big data analysis technology to obtain the real needs of teachers, and look for the correlation between the training demand target and the training content data. This will further improve the pertinence and effectiveness of the training content and achieve a seamless connection between training content and training needs (Wu \& $\mathrm{Li}, 2014)$.

Taking Fujian Province, China as an example, the Fujian Provincial Basic Education Network uses the Fujian Education Institute Training Management Information Archive and the Fujian Provincial Elementary and Middle School teachers' Continuing Education Information Management System Platform. Conduct in-depth training needs surveys of teachers in elementary and middle schools in the province according to the dimensions of region, gender, title, semester, subject, etc., and use big data statistics and analysis techniques to obtain information on teacher training needs, and then maximize the implementation of "on-demand training for you" Design "concept of teacher training in elementary and middle schools (Fan, 2016).

\section{Focus on Resource Integration, and Build a Multi-Win-Win Teacher Continuing Education Ecosystem}

As a product of "Internet+ Education", "MOOC" uses the Internet to successfully push high-quality educational resources to the world and realize global sharing. In continuing teacher education, we should also focus on resource integration. Through the application of cloud computing, excellent resources can be reconfigured, integrated, and shared within a very wide range ( $\mathrm{Li}, 2012)$.

With the free, open, efficient, and convenient characteristics of the Internet, the dissemination of high-quality resources for teacher training is not limited by time and space, so that its role and value can be exerted and extended, so that more teachers can obtain resource services. On the one hand, teachers can use the platform for online communication and exchange, experience and share learning fun and resources with each other in the learner circle, and realize the interaction and sharing of teaching resources between teachers and teachers. On the other hand, the use of cloud platforms 
can effectively break through the outstanding problems of imbalanced educational resources caused by traditional factors such as geography, inter-school, time, funding, and teachers. Colleagues from prestigious regional and high-quality universities share highquality resources on the same training platform to build a win-win ecosystem (Fan, 2016).

\section{Strengthen the Evaluation of Online Learning to Ensure the Quality of Continuing Education for Teachers}

Some scholars have suggested that "the teacher's conscious and reflective practice means that the teacher is the subject of learning and constructing knowledge from his own experience" (Marili \& Benedito, 2016). Therefore, strengthening evaluation in teachers' continuing education can promote teachers' systematic thinking and reflection on their behaviors and effects as learners, so as to improve the quality of continuing education.

Since distance network continuing education cannot be supervised during the training process like the traditional model, there are some teachers who lack selfregulation due to active learning. As a result, the quality of network distance teacher continuing education cannot be guaranteed. Therefore, it is necessary to strengthen learning evaluation in the process of continuing education on the network, use the network to monitor and diagnose the participation of teachers, and accurately evaluate their learning effects, in order to stimulate and urge participating teachers to complete the tasks of network training and learning.

Take a shared platform for the practice of wisdom of a elementary and middle school principal in Ningbo City, Zhejiang Province, China as an example. This platform has adopted some technical measures and management methods to strengthen the process monitoring of remote training and improve the authenticity of training (Yuan, 2018).

First, set up learning intermediate tasks. Questions pop up on the screen every 15 minutes in the training video, and the questions are the content learned in the first 15 minutes to ensure the continuity and authenticity of the learning.

Second, implement training task management. The website platform sets the corresponding training quantity and quality requirements for the content of the training task module. The platform will automatically record the e-learning progress of each college and the required completion deadline, and present the progress on the platform, so that managers can monitor and supervise and compare and evaluate students with each other in a timely manner. Students who do not complete the required content in accordance with the requirements will not be able to obtain corresponding continuing education credits.

Third, give play to multiple evaluation mechanisms. Through the pre-test and post-test of network training activities, carefully monitor the educational status of their participating teachers, conduct comprehensive testing and evaluation of the results of 
teachers' network training, and promote the successful completion of teacher training tasks. At the same time, through peer evaluation, platform automatic evaluation, selfevaluation, and evaluation by the leader of the training group, teachers' autonomy is enhanced, and participating teachers are urged and motivated to carry out online training and learning, so that they continue to obtain positive professional advancement.

\section{Conclusions}

Teachers play an important role in the teaching process and "play a vital role in achieving learning goals" (Ekrem, 2016). "Teachers must receive on-the-job training in their careers to keep up with innovation in their field" (Ada \& Ustin, 2008). In the Internet era, not only have teachers changed their educational concepts or teaching methods, but their continuing education models also need to be changed and reformed accordingly. Network technology has become the main technical support for current teacher training due to its resource sharing, multimedia and interactivity. The continuing education of elementary and middle school teachers should make full use of the advantages of network technology to improve the continuing education methods of teachers, realize the close cooperation between network training and centralized face-to-face training and on-site practical training, and jointly promote the professional development of basic education teacher training

\section{References}

Ada, S., Ustin, A. (2008). Isvec egitim sisteminin incelenmesi. Kazm Karabekir Egitim Fakiltesi Dergisi, 17:146-173.

Chen Z. (2015) The impact of wisdom education on teachers'professional development .Edu Info Technol, 5:13-15.

Fan G. (2016) Exploration and strategy thinking of teacher training models in elementary and middle schools under the background of "internet +": taking fujian basic education network as an example. Teacher Train Elem Mid Sch, 3:13-17

Gou J., Ji W., Yu Y. (2019) Analysis on the status quo and problems of professional development training for college teachers under the background of "internet +". J Tianjin TV Univ, 6(2):52-61.

He Z., Lu H., Yin A. (2019) Research on smart classroom from the perspective of precision teaching: taking smart classroom construction in Dazu district of Chongqing as an example. Modern Edu Technol, 10:115-120.

Ji W. Teacher professional development under the background of educational informationization. Higher Edu Res, 2005 (9).

Li X. (2012) Modular exploration of teacher training courses in elementary and middle 
schools under network environment .Chin Teacher, 9:32-34.

Liu P., Xiong J., Hu R., Li X., Du L., Pan J., Ling Y. (2018) Research on the application of blended teaching in adult continuing education. Further Edu, (5):42-44.

Manuela, R. (2013) Using Network and Mobile Technology to Bridge Formal and Informal Learning. Chandos Learn Teach Ser, 183-207.

Marili, M.da S.V., Benedito, G.A.N. (2016) Peer instruction: continuing teacher education in higher education. Procedia-Soc Behav Sci, 217:249-256.

Shi L., Yuan C. (2017) Reform and innovation of teachers' continuing education model under the background of "internet +". Element Mid Sch Teacher Train, (12):21-23.

State Affairs of the Central Committee of the Communist Party of China. Opinions of the State Council of the Central Committee of the Communist Party of China on Comprehensively Deepening the Reform and Construction of Teachers in the New Era [EB/OL]. Accessed to:

Http://www.gov.cn/zhengce/201801/31/content_5262659.htm, 2018-131/2019-10-21

Tang Y., Wang M., Pang J., Zhong S., Wang W. (2015) Research on the intelligent teacher training model under the blended learning environment .Electr Edu Res, (8):108-112.

Wei T. (2018) Professional development of rural teachers under the background of "internet +" .teaching and management, 2:69-71.

Wu L., Li L. (2014) Training, learning and development: intergenerational research on teachers' distance training platform. Chin Edu Technol, (11):74-79.

Yu T. (2014) From "starring" to "director": teachers' role transformation and its path in the basic education flip classroom .Shanghai Edu Res, (5).

Yuan L. (2018) Research on sharing mechanism of practice wisdom of elementary and Middle School Principals: Taking Ningbo"s Famous Principals Studio as an Example. Element Mid Sch Teacher Train, (12):27-30.

Zeng J. (2006) The Change of teachers' role in the background of educational informationization. Reform Strategy, (6).

Zhang Q., Sun M. (2019) Problems and countermeasures of teacher training in elementary and middle schools. Heilongjiang Edu Theory Pract, (1-2):114-115.

Zhu L. (2019) Optimization strategies for teacher training under the background of “internet +". Curric Edu Res, (8):204-205. 